\title{
Transabdominal Ultrasonographic Evaluation of Pelvic Masses and Comparsion with Transvaginal Ultrasonography
}

\author{
V. Tamilarasan ${ }^{1}$, Md. Ameen ${ }^{2}$, Vinay Jadhav ${ }^{3}$ \\ ${ }^{1}$ Assisstant Professor, Department of Radiology, ${ }^{2}$ Professor and Hod, Department of Radiology, ${ }^{3}$ Assisstant Professor, \\ Department of Radiology, Trichy SRM Medical College, Hospital and Research Centre, India
}

Corresponding author: Dr. V. Tamilarasan, SRM Doctors Quarters F-Block No:17, SRM Medical College, Hospital and Research Centre, IRUNGALUR, Trichy, India

DOI: http://dx.doi.org/10.21276/ijcmsr.2019.4.3.19

How to cite this article: V. Tamilarasan, Md. Ameen, Vinay Jadhav. Transabdominal ultrasonographic evaluation of pelvic masses and comparsion with transvaginal ultrasonography. International Journal of Contemporary Medicine Surgery and Radiology. 2019;4(3):C86-C89.

\section{A B S T R A C T}

Introduction: Pelvic masses of gynaecological or non-gynaecological origin are one of the common conditions encountered in clinical practice. Trans vaginal Ultrasonography plays a vital role in confirmation and classification. But due to it's limited availability, clinicians in resource poor settings, often rely on transabdominal ultrasonography. Present study assessed the diagnostic accuracy of Transabdominal Ultrasonography, as compared to Transvaginal Ultrasonography.

Material and methods: A diagnostic accuracy study was conducted for one years. Total of 80 participants who presented with history, symptoms, and signs suggestive of pelvic mass were recruited. Sensitivity and specificity and predictive values were calculated.

Results: Majority (47.5\%) of the lesions were of uterine origin as per USG sites. Transabdominal USG diagnosis showed $28.75 \%$ of lesions to be originating from ovaries. Transvaginal USG diagnosis depicted $48.64 \%$ of fibroid cases. Transabdominal ultrasound had a sensitivity of $92.00 \%$ and a specificity of $100 \%$ in diagnosing fibroid. It showed an overall sensitivity of $93.34 \%$ and specificity of $100 \%$. In diagnosis of ovarian lesions, Ultrasonography by using IOTA scoring system showed $98.45 \%$ sensitivity and $100 \%$ specificity.

Conclusion: Transabdominal sonography has proved to be a very useful highly diagnostic and a reliable method with good sensitivity and specificity.

Keywords: USG diagnosis, IOTA Scoring System, Pelvic Masses

\section{INTRODUCTION}

The female pelvis is a complex anatomical region, comprising of few important organs and systems performing different and independent functions. The uro-genital system and portions of other organs and systems usually generate pelvic masses even in para-physiologic conditions. ${ }^{1}$ Most pelvic masses are diagnosed through classical physical examination, including rectovaginal examination. Ultrasound plays a vital role in diagnosis and classification of symptomatic and sometimes asymptomatic pelvic masses. ${ }^{2}$

Pelvic masses may present with wide range of clinical findings or sometimes may remain asymptomatic and diagnosed accidentally during routine pelvic examination The classic complaints observed are pain, pressure sensations, dysmenorrhea, or abnormal uterine bleeding. Considering pelvic masses as acquired lesions, a few emerge as congenital anomalies. Laboratory tests prove less informative in the evaluation of pelvic masses, but levels of serum $\beta$-human chorionic gonadotropin (hCG) or tumor markers may be helpful. The treatment protocol has variations depending on symptoms, age, and risk factors related to patient. ${ }^{3}$

Most pelvic masses are diagnosed through classical physical examination, including rectovaginal examination and Ultrasound can reveal asymptomatic pelvic masses. ${ }^{2}$ Sonography usually provides clinically important parameters for the evaluation of pelvic mass. Pelvic sonography can confirm the presence or absence of a suspected pelvic mass. ${ }^{4}$ Transvaginal sonography is suggested as the first line imaging modality for reproductive age women with acute pelvic pain due accessibility, lesser ionizing radiation and efficiency in identifying female reproductive tract disorders. ${ }^{5}$ Transabdominal approach in obstetrics and gynaecology is conducted to identify possible pelvic pathology or pregnancy in a less invasive manner. ${ }^{6}$

The present study was conducted with aims and objectives to study the Transabdominal and Transvaginal Ultrasonographic findings of various pelvic masses, to know the sensitivity, specificity and reliability of Ultrasonographic Findings of pelvic masses, and also to know the sensitivity, specificity and predictive value of ultrasonography of Benign and malignant masses.

The present study was conducted to study diagnostic utility of Transabdominal Ultrasonography against transvaginal ultrasonography in diagnosis of various pelvic masses. 


\section{MATERIAL AND METHODS}

Study was done on 80 cases who presented with history, symptoms, and signs of pelvic mass were recruited from SRM medical College and Hospital, Trichy. It was a one year study from April 2018 to March 2019. Patients were properly counselled and gave informed consent before entry into the study.

Study procedure: All of them were subjected to Transabdominal Ultrasonography with full bladder technique with $\mathrm{C} 1-5 \mathrm{MHz}$ probe and then Transvaginal Sonography with empty bladder technique with E8CS MHz except for the unmarried female patients. TAB and TVS was performed with the use of GE LOGIQ P9 Diagnostic Ultrasound System. Observations included size, shape and echo texture of the pelvic masses in sagittal and transverse planes. IOTA scoring system was applied to differentiate benign and malignant ovarian tumors.

Female patients [pre pubertal to post-menopausal] of all age group presenting with symptoms like pain in abdomen/pelvis, PV bleeding, PV white discharge, urinary and gastrointestinal pressure symptoms and palpable mass and those pelvic mass detected at time of routine pelvic examination or at the time of Ultrasonography [Transabdominal and Transvaginal Sonography] done for other diagnosis were included in study. Women on ovulation induction drugs and Normal Pregnancy were excluded from study.

\section{STATISTICAL ANALYSIS}

Transabdominal USG was considered as gold standard. Transvaginal was considered as screening test. The sensitivity, specificity, predictive values and diagnostic accuracy of the screening test along with their 95\% CI were presented.

\section{RESULTS}

The maximum number of cases were in the age group of 31 -50 years and the minimum number were in the age group of 61 - 70 years.

Majority (40\%) of participants had DUB. The proportion of Pelvic mass, Cx mass, Mass P/A was 36.25\%, 6.25\% and $5 \%$ respectively. PID and Lt. Ov torsion was $3.75 \%$ for each respectively. (Table 1 )

Majority of the lesions were uterine origin (47.5\%). The proportion of Left ovary, Cervix, Right ovary was $11.25 \%$,

\begin{tabular}{|l|c|c|}
\hline Clinical Diagnosis & No. of Cases & \% of Cases \\
\hline DUB & 32 & 40 \\
\hline Pelvic mass & 29 & 36.25 \\
\hline Cx mass & 05 & 6.25 \\
\hline Mass P/A & 04 & 5 \\
\hline PID & 03 & 3.75 \\
\hline Lt. Ov torsion & 03 & 3.75 \\
\hline Rt. Ov torsion & 01 & 1.25 \\
\hline Ectopic pregnancy & 02 & 2.5 \\
\hline Appendicitis & 01 & 1.25 \\
\hline Total & 80 & 100 \\
\hline \multicolumn{2}{|c|}{ Table-1: Descriptive analysis of clinical diagnosis in the study } \\
population (N=80) \\
\hline \multicolumn{2}{|c|}{} \\
\hline
\end{tabular}

6.25\% and 10\% respectively, Endometrial cavity and Right adnexa was $7.5 \%$ for each respectively. (table 2 )

Majority (45\%) had fibroid on Transabdominal USG Diagnosis, followed by Ovarian lesions was 28.75\%, Adenomyosis, Endometrial polyp and Ca Cervix was 5\% for each respectively. Majority (48.64\%) had fibroid on transvaginal USG Diagnosis, followed by Ovarian lesions was $29.2 \%$, Adenomyosis, Endometrial polyp and Ca Cervix was $5.4 \%$ for each respectively. (Table 3 )

Among the study population, 4 (11.12\%) participants had sub serosal fibroid, 29 (80.55\%) participants had Intramural

\begin{tabular}{|l|c|c|}
\hline USG Site of Lesion & No. of Cases & \% of Cases \\
\hline Uterus & 38 & 47.5 \\
\hline Cervix & 05 & 6.25 \\
\hline Endometrial cavity & 06 & 7.5 \\
\hline Right ovary & 08 & 10 \\
\hline Left ovary & 09 & 11.25 \\
\hline Bilateral ovaries & 02 & 2.5 \\
\hline Right adnexa & 06 & 7.5 \\
\hline Left adnexa & 04 & 5 \\
\hline Pelvis & 02 & 2.5 \\
\hline Total & 80 & 100 \\
\hline
\end{tabular}

Table-2: Descriptive analysis of USG site of lesion in the study population $(\mathrm{N}=80)$

\begin{tabular}{|l|c|c|}
\hline $\begin{array}{l}\text { Transabdominal USG Diagnosis } \\
\text { (N=80) }\end{array}$ & $\begin{array}{c}\text { No. of } \\
\text { Cases }\end{array}$ & $\begin{array}{c}\text { \% of } \\
\text { Cases }\end{array}$ \\
\hline Fibroid & 36 & 45 \\
\hline Adenomyosis & 4 & 5 \\
\hline Endometrial polyp & 4 & 5 \\
\hline Ca Cervix & 4 & 5 \\
\hline Vesicular mole & 1 & 1.25 \\
\hline Ectopic pregnancy & 2 & 2.5 \\
\hline Hydrosalphinx & 1 & 1.25 \\
\hline Ovarian torsion & 3 & 3.75 \\
\hline Ovarian lesions & 23 & 28.75 \\
\hline Pelvic abscess & 2 & 2.5 \\
\hline Transvaginal USG diagnosis (N=72) & No. of & $\%$ of \\
& Cases & Cases \\
\hline Fibroid & 36 & 48.64 \\
\hline Adenomyosis & 4 & 5.4 \\
\hline Endometrial polyp & 4 & 5.4 \\
\hline Ca Cervix & 4 & 5.4 \\
\hline Vesicular mole & 1 & 1.35 \\
\hline Ectopic pregnancy & 2 & 2.7 \\
\hline Ovarian lesions & 21 & 29.2 \\
\hline Table-3: Descriptive analysis of USG diagnosis in the study \\
\hline \multicolumn{2}{|c|}{ population } & \\
\hline
\end{tabular}

\begin{tabular}{|l|c|c|}
\hline Type of Fibroid & No. of Cases & \% of Cases \\
\hline Subserosal & 04 & 11.12 \\
\hline Intramural & 29 & 80.55 \\
\hline Submucosal & 03 & 8.33 \\
\hline Total & 36 & 100 \\
\hline
\end{tabular}

Table-4: Descriptive analysis of types of fibroid encountered in the study population $(\mathrm{N}=36)$ 


\begin{tabular}{|l|c|c|c|c|c|}
\hline Type of Pelvic mass & Sensitivity & Specificity & PPV & NPV & Accuracy \\
\hline Fibroid & $92 \%$ & $100 \%$ & $100 \%$ & $92.59 \%$ & $96 \%$ \\
\hline Adenomyosis & $92.59 \%$ & $100 \%$ & $100 \%$ & $93.10 \%$ & $96.25 \%$ \\
\hline Endometrial polyp & $92.59 \%$ & $100 \%$ & $100 \%$ & $93.10 \%$ & $96.25 \%$ \\
\hline Ca cervix & $92.59 \%$ & $100 \%$ & $100 \%$ & $93.10 \%$ & $96.25 \%$ \\
\hline Vesicular mole & $92.59 \%$ & $100 \%$ & $100 \%$ & $93.10 \%$ & $96.25 \%$ \\
\hline Ectopic pregnancy & $92.59 \%$ & $100 \%$ & $100 \%$ & $93.10 \%$ & $96.25 \%$ \\
\hline Ovarian lesion & $98.45 \%$ & $100 \%$ & $98.45 \%$ & $98.47 \%$ & $99.2 \%$ \\
\hline
\end{tabular}

Table-5: Comparison of diagnostic accuracy Transabdominal ultrasonography against transvaginal ultrasonography in various pelvic masses.

fibroid and 3 (8.33\%) participant ha submucosal fibroid. (Table 4)

In diagnosing fibroids, transabdominal US had a sensitivity and specificity of $92 \%$ and $100 \%$ respectively. The overall diagnostic accuracy was 96\%. In diagnosis adenomyosis, Endometrial polyp, Ca cervix, Vesicular mole, and Ectopic pregnancy transabdominal US had a sensitivity and specificity of $92.59 \%$ and $100 \%$ respectively. The overall diagnostic accuracy was $93.1 \%$. In diagnosis ovarian lesion, transabdominal US had a sensitivity and specificity of $98.45 \%$ and $100 \%$ respectively. The overall diagnostic accuracy was 98.47\%. (Table 5)

\section{DISCUSSION}

Present study showed majority of the cases were uterine fibroid (45\%) and Transvaginal Ultrasound in fibroid had a sensitivity of $92.00 \%$ and a specificity of $100 \%$. A retrospective study projected results that transvaginal sonography was more accurate over transabdominal sonography in evaluating pelvic masses. ${ }^{7}$

Study conducted by Giuseppe Loverro et al. ${ }^{8}$ results depicted as a test for the detection of uterine cavity abnormalities, TVS in comparison with hysteroscopy had $84.5 \%$ sensitivity and $98.7 \%$ specificity, $98.0 \%$ positive predictive value and $89.2 \%$ negative predictive value. Results stated that 4 cases of adenomyosis are detected while 2 cases were wrongly diagnosed as fibroid on Transabdominal scan, which turned out to be adenomyosis of uterus on Transvaginal Scan.

Another research showed TVS was better to diagnose endometrial polyps, submucosal fibroids, nabothian cysts and adenomyosis while TAS seen superior in cases of bulky uterus. $^{9}$

A total of 4 cases of Carcinoma cervix were detected on Transabdominal scan and confirmed by Transvaginal Scan. A study showed Sensitivity of TAS and TVS to diagnose Ca cervix $57.1 \%$ and $78.6 \%$, specificity $89.7 \%$ and $92.3 \%$, positive predictive value $66.9 \%$ and $78.6 \%$, negative predictive value $85.4 \%$ and $92.3 \%$, and accuracy $81.1 \%$ and $88.7 \%$ respectively which concluded uterine mass can be evaluated more accurately by TVS than TAS. ${ }^{10}$

In the current study by using IOTA scoring system, Transvaginal Ultrasound in ovarian lesions had a sensitivity of $98.45 \%$ and specificity of $100 \%$. Out of 23 cases, 16 cases showed benign ovarian lesions and 7 cases showed malignant ovarian lesions. Similar study conducted by Giovanni Serafini et,al. ${ }^{11}$ stated that transvaginal sonography identified one small previously undetected tumor but was not able to image the entire extent and it recognized actual uterine origin of an eccentric pelvic mass.

Asim Kurjak et al. ${ }^{12}$ found the sensitivity $96.4 \%$, specificity $99.8 \%$, and positive predictive value $98.2 \%$ of transvaginal color ultrasound.

In one research adnexal findings highly suspicious for ectopic pregnancy were found in $68 \%$ of cases by transabdominal ultrasonography and in $84 \%$ by transvaginal ultrasonography. ${ }^{13}$ In current study 2 cases of ruptured ectopic pregnancies were detected.

A study reported that TAS had a limited diagnostic capacity for adenomyosis but also that TVS alone was poor in patients with an enlarged uterus. ${ }^{14}$ In present study 2 cases were wrongly diagnosed as fibroid on Transabdominal scan, turned out to be adenomyosis of uterus on Transvaginal Scan. Another study reported TVS as sufficiently accurate tool for diagnosis of adenomyosis in clinically suspected cases, but not in unselected premenopausal women with myomas. ${ }^{15}$

Strengths of study: Present study has followed detailed procedure of both the methods used.

Limitations of the study: The sample size was less hence study cannot be generalized.

\section{CONCLUSION}

Transabdominal and Transvaginal sonography with a good equipment when appropriately performed by an experienced radiologist, using a proper methodology and standard guidelines has proved to be a very useful highly diagnostic and a reliable method with good sensitivity and specificity. It thus has become an indispensable tool for the diagnosis, management and follow up of all cases with pelvic mass.

\section{REFERENCES}

1. Alessandrino F, Dellafiore C, Eshja E, Alfano F, Ricci G, Cassani C, et al. Differential diagnosis for female pelvic masses. Medical Imaging in Clinical Practice: IntechOpen; 2013.

2. Schutter EM, Kenemans P, Sohn C, Kristen P, Crombach G, Westermann R, et al. Diagnostic value of pelvic examination, ultrasound, and serum CA 125 in postmenopausal women with a pelvic mass. An international multicenter study. Cancer. 1994;74(4):1398-406.

3. Barbara L, Hoffman, John O, Schorge, Joseph I, Schaffer, et al. Pelvic Mass. Williams Gynecology. 2nd ed: McGraw-Hill Education; 2012

4. Ljubic A, Bozanovic T, Vilendecic Z. Sonographic 
evaluation of benign pelvic masses. Donald School Basic Textbook of Ultrasound in Obstetrics and Gynecology. 2014;372.

5. Ohngemach DJ, Esterson YB, Rahman N, Noor A, Pellerito JS. Unexpected Findings During Evaluation of Acute Pelvic Pain With Transvaginal Sonography. J Ultrasound Med. 2016;35(12):2687-96.

6. Kurzweil A, Martin J. Transabdominal Ultrasound. [Updated 2019 Jan 9]. In: StatPearls [Internet]. Treasure Island (FL): StatPearls Publishing; 2019 Jan. Available from: https://www.ncbi.nlm.nih.gov/books/ NBK534813/.

7. Leibman AJ, Kruse B, McSweeney MB. Transvaginal sonography: comparison with transabdominal sonography in the diagnosis of pelvic masses. AJR Am J Roentgenol. 1988;151(1):89-92.

8. Loverro G, Nappi L, Vicino M, Carriero C, Vimercati A, Selvaggi L. Uterine cavity assessment in infertile women: comparison of transvaginal sonography and hysteroscopy. Eur J Obstet Gynecol Reprod Biol. 2001;100(1):67-71.

9. Solih M, Jha A, Joshi B. Abnormal Uterine Bleeding: Comparison of Transabdominal and Transvaginal Sonography. J Inst Med. 2018;42(1).

10. Dipi RM, Amin MS, Islam MN, Khan NA, Chaiti MM, Hossain MM. Comparison of transabdominal and transvaginal sonography in the evaluation of uterine mass with histopathological correlation. Mymensingh Med J. 2013;22(1):69-74.

11. Serafini G, Martinoli C, Quadri P, Speca S, Crespi $\mathrm{G}$, Venturino E. Lipomatous tumors of the uterus: ultrasonographic findings in 11 cases. J Ultrasound Med. 1996;15(3):195-99; quiz 201-2.

12. Kurjak A, Zalud I, Alfirevic Z. Evaluation of adnexal masses with transvaginal color ultrasound. J Ultrasound Med. 1991;10(6):295-7.

13. Kivikoski AI, Martin CM, Smeltzer JS. Transabdominal and transvaginal ultrasonography in the diagnosis of ectopic pregnancy: a comparative study. Am J Obstet Gynecol. 1990;163(1):123-8.

14. Bazot M,Darai E,RougerJ,Detchev R,CortezA,Uzan S. Limitations of transvaginal sonography for the diagnosis of adenomyosis, with histopathological correlation. Ultrasound Obstet Gynecol. 2002;20(6):605-11.

15. Dueholm M. Transvaginal ultrasound for diagnosis of adenomyosis: a review. Best Pract Res Clin Obstet Gynaecol. 2006;20(4):569-82.

Source of Support: Nil; Conflict of Interest: None

Submitted: 23-06-2019; Accepted: 22-07-2019; Published online: 14-08-2019 